\title{
A PERFORMANCE EVALUATION FRAMEWORK FOR CONTACT CENTER OUTSOURCING PARTNER BASED ON BSC AND FAHP
}

\section{SOONHU SOH}

Division of Business Administration, Wonkwang University, Republic of Korea

ABSTRACT
Under rapidly changing competitive environment, contact center outsourcing, which allows companies to outsource
contact center functions to external specialized service providers, is an important strategic decision for achieving
sustainable competitive advantage. The selection process of an appropriate outsourcing partner, involving multiple criteria
and alternatives, may be one of the most complex decision makings. In this point, this study proposes a useful way how to
choose the best one among potential contact center outsourcing partners based on Balanced Scorecard (BSC) and Fuzzy
Analytic Hierarchy Process (FAHP) approach. And the process of evaluation and selection suggested in this study is
shown in detail through a empirical case study. The proposed evaluation framework and methodology can be applied to the
certification program for contact center services.
KEYWORDS: Contact Center, Outsourcing, Key Performance Indicators, Balanced Scorecard, Analytic Hierarchy
Process, Fuzzy Set Theory

Received: Jun 08, 2020; Accepted: Jun 28, 2020; Published: Sep 14, 2020; Paper Id.: IJMPERDJUN20201207

\section{INTRODUCTION}

The fourth industrial revolution, which is characterized by disruptive technologies such as Artificial Intelligence (AI), Internet of Things (IoT) and Big Data, is changing the way businesses interact with their customers. Along with this change traditional call centers are evolving into multichannel or omnichannel contact centers that allow communication with customers through various means including phone, e-mail, live chat and social media. In order to deliver a better customer experience across every touchpoint, many businesses are choosing to outsource their customer service operations to a specialized contact center company.

One of the most important issues in contact center outsourcing is the performance evaluation of outsourcing service providers. In practice, this problem has been attracted much attention from the academic and industrial researchers. However, most of studies merely listed some of the evaluation criteria but did not present an integrated and systematic framework for evaluating the performance of outsourcing service providers. For this reason, this study applies the Balanced Scorecard (BSC) proposed by Kaplan and Norton (1992) to develop a performance evaluation framework for contact center outsourcing.

The performance evaluation of outsourcing service providers can be regarded as a Multiple Criteria Decision Making (MCDM) problem, in which decision alternatives are evaluated on multiple conflicting criteria. One of the most widely used methods for MCDM is the Analytic Hierarchy Process (AHP) developed by Saaty (1980). In classical AHP, crisp values are used to represent the decision maker's subjective judgment. But this method is incapable of handling the uncertainty inherent in transforming decision maker's imprecise judgment into an exact number (Chan and Kumar, 2007). Considering this limitation, this study combines the classical AHP 
method with fuzzy set theory formalized by Zadeh (1965) in order to accurately capture the decision maker's judgment by using fuzzy numbers instead of crisp numbers.

In accordance with the above discussion, this study aims to develop a decision framework for performance evaluation of contact center outsourcing partner based on BSC and FAHP approach. With this goal, the paper proceeds as follows. The second section briefly introduces the BSC and FAHP. In the third section an empirical case study is presented to demonstrate the applicability of the proposed framework and approach. The fourth section concludes with a discussion of practical implications and suggestions for further research.

\section{CONTACT CENTER BALANCED SCORECARD}

Almost every company today has a contact center to build effective and efficient customer relationship management. As more than $70 \%$ of all customer-business interactions are handled in contact centers (Feinberg et al, 2002), positive contact center experiences are critically important for customer satisfaction and ultimately business success. For this reason, more and more companies are outsourcing their contact center operations to third-party specialized service providers. According to a report published by Adroit Market Research (2019), the global contact center outsourcing market was valued at $\$ 88.62$ billion in 2018 and is expected to grow to $\$ 131.56$ billion at a CAGR of 5.05\% through 2025.

Once the contact center outsourcing decision is made, the next critical phase is the evaluation and selection of the sustainable outsourcing partner. Partnering with the right outsourcing service provider enables companies to benefit from cost savings, service quality improvements, technical expertise and operational efficiencies (Namasivayam, 2004). For a sustainable outsourcing relationship, it is important to determine the key performance indicators (KPIs)that can be used to evaluate and monitor the overall performance of the outsourcing service provider. The Center for Customer Driven Quality (CCDQ) at Purdue University suggested the KPIs of contact center by classifying into the operation related indicators, income related indicators, cost related indicators and service quality related indicators (Anton, 1997). The Customer Operations Performance Center (COPC), the world's leading authority on contact center operations management, evaluates the operational level of a contact center using a total of 32 measurement indicators for the four key areas of leadership and planning, processes, people, and performance (Cheonget al, 2008). The Korean Agency for Technology and Standards (2006) has established national standard for contact center services, KS S 1006, that specifies the performance requirements from the customer perspective.

This study adopts BSC as a framework for evaluation criteria of outsourcing partners. The BSC, according to Kaplan and Norton (1992, p.32), is a new framework or structure created for integrating indicators derived from the strategy on the four perspectives such as the financial, the customers, the processes and the perspective of learning and growth, and its indicators are derived from an explicit and rigorous translation of the strategy of the organization into tangible objectives and indicators.After reviewing the related literature, the most frequently used KPIs were selected and then organized based on four perspectives of BSC in order to evaluate the performance of contact center outsourcing partners, as shown in Figure 1. 


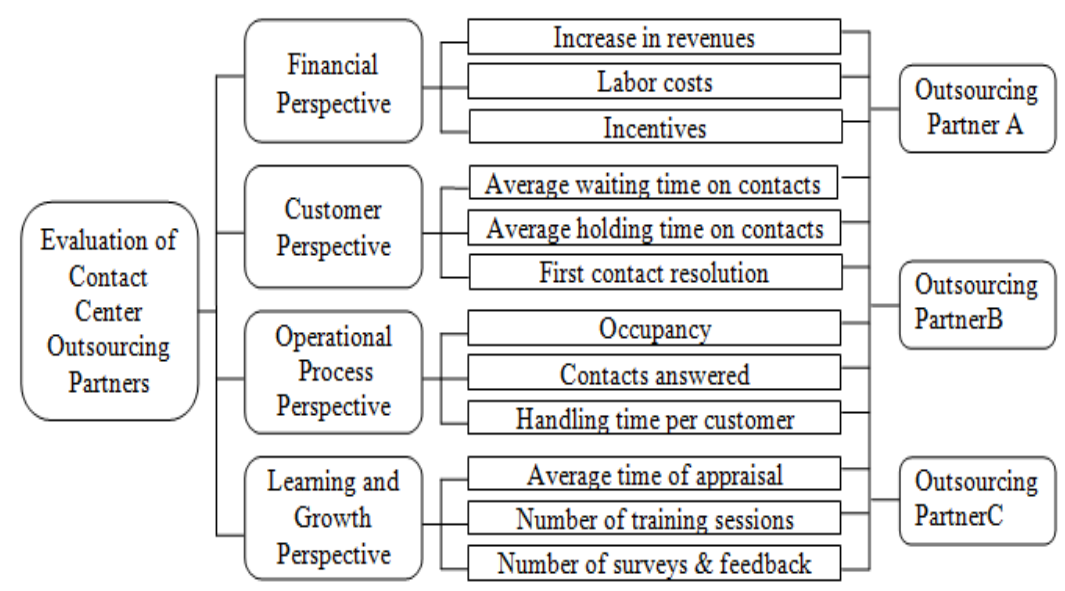

Figure 1: Hierarchy Structure for Evaluation Criteria of Contact Center Outsourcing Partner Selection.

\section{FUZZY ANALYTIC HIERARCHY PROCESS}

Evaluating and selectingoutsourcing partners is a MCDMproblem where many conflicting criteria should be considered in decisionmaking process. The AHP is one of the commonly adopted methods used in determining the relative importance of a set of attributes or criteria. Many researchers have applied the AHP to solve the MCDM problems in a number of different areas such as engineering design, economic planning, energy policy, project selection, budget allocation, etc (El Khayyamand Herrou, 2018). However, one of the main obstacles of AHP is its inability to precisely handle the inherent uncertainty or vagueness associated with the mapping of the decision-maker's judgment to a number. In many practical cases the decision maker could be imprecise about their own level of preference, due to incomplete information or knowledge, the vagueness of the human thinking, and the inherent complexity and uncertainty of the decision environment. It is therefore difficult for the decision maker to express the pairwise comparison judgments as exact numerical values on a ratio scale. In order to eliminate this limitation, it is more natural to express the comparison ratios as interval number or fuzzy sets since they are suitable to represent uncertain human judgments. For this reason, this study applies FAHP in obtaining criteria weights.

In FAHP, the triangular fuzzy numbers are used in the pairwise comparison process to express subjective judgments. As shown in Figure 2, triangular fuzzy numbers are defined by three real numbers, expressed as $(l, m, u)$. The parameters $l, m$, and $u$, respectively, indicate the smallest possible value, the most promising value, and the largest possible value that describe a fuzzy event. Their membership functions are described as equation (1).

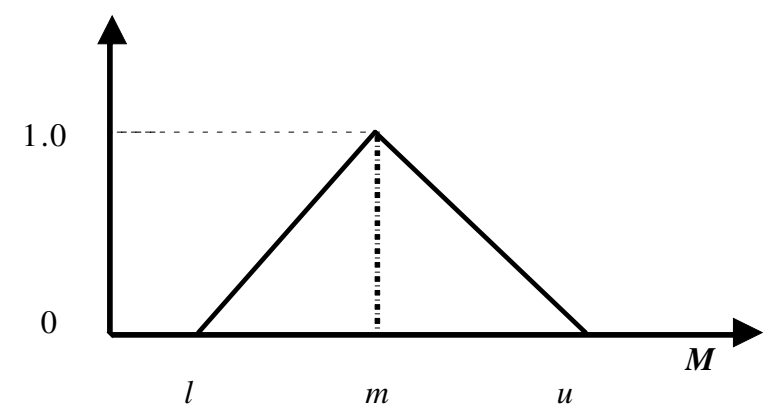

Figure 2: Triangular Fuzzy Number, M. 


$$
\mu(x / \tilde{M})= \begin{cases}0, & x<l \\ (x-l) /(m-l), & l \leq x \leq m \\ (u-x) /(u-m) & m \leq x \leq u \\ 0, & x>u\end{cases}
$$

The linguistic variables matching triangular fuzzy numbers and the corresponding membership functions are provided in Table 1.

Table 1 Shows In this study the extent FAHP is utilized, which was originally introduced by Chang (1996). The main steps of fuzzy extent analysis conducted in this study are as follows (Soh, 2010):

Table 1: Triangular Fuzzy Conversion Scale

\begin{tabular}{|c|c|c|}
\hline Linguistic Scale & Triangular Fuzzy Number & Triangular Fuzzy Reciprocal Number \\
\hline Equally important & $(1,1,1)$ & $(1,1,1)$ \\
Weakly more important & $(2 / 3,1,3 / 2)$ & $(2 / 3,1,3 / 2)$ \\
Strongly more important & $(3 / 2,2,5 / 2)$ & $(2 / 5,1 / 2,2 / 3)$ \\
Very strongly more important & $(5 / 2,3,7 / 2)$ & $(2 / 7,1 / 3,2 / 5)$ \\
Absolutely more important & $(7 / 2,4,9 / 2)$ & $(2 / 9,1 / 4,2 / 7)$ \\
\hline
\end{tabular}

- The value of fuzzy synthetic extent with respect to the $i$-th object is defined as

$$
S_{i}=\sum_{j=1}^{m} M_{i j} \otimes\left[\sum_{i=1}^{n} \sum_{j=1}^{m} M_{i j}\right]^{-1}
$$

where $\sum_{j=1}^{m} M_{i j}=\left(\sum_{j=1}^{m} l_{j}, \sum_{j=1}^{m} m_{j}, \sum_{j=1}^{m} u_{j}\right) \sum_{i=1}^{n} \sum_{j=1}^{m} M_{i j}=\left(\sum_{i=1}^{n} l_{i}, \sum_{i=1}^{n} m_{i}, \sum_{i=1}^{n} u_{i}\right)$ and $\left[\sum_{i=1}^{n} \sum_{j=1}^{m} M_{i j}\right]^{-1}=\left(\frac{1}{\sum_{i=1}^{n} u_{i}}, \frac{1}{\sum_{i=1}^{n} m_{i}}, \frac{1}{\sum_{i=1}^{n} l_{i}}\right)$.

- As $\tilde{M}_{1}=\left(l_{1}, m_{1}, u_{1}\right)$ and $\tilde{M}_{2}=\left(l_{2}, m_{2}, u_{2}\right)$ are two triangular fuzzy numbers, the degree of possibility of $M_{1}=\left(l_{1}, m_{1}, u_{1}\right) \geq M_{2}=\left(l_{2}, m_{2}, u_{2}\right)$ is defined as

$$
V\left(\tilde{M}_{1} \geq \tilde{M}_{2}\right)=\operatorname{height}\left(\tilde{M}_{1} \cap \tilde{M}_{2}\right)=\mu_{M_{1}}(d)=\left\{\begin{array}{lll}
1, & \text { if } m_{1} \geq m_{2} \\
0, & \text { if } l_{2} \geq u_{1} \\
\frac{l_{1}-u_{2}}{\left(m_{2}-u_{2}\right)-\left(m_{1}-l_{1}\right)}, & \text { if } \quad m_{2} \geq m_{1}
\end{array}\right.
$$

- The degree possibility for a convex fuzzy number to be greater than $k$ convex fuzzy $M_{i}(i=1,2, \ldots, k)$ numbers can be defined by

$$
\begin{aligned}
& V\left(M \geq M_{1}, M_{2}, \ldots, M_{k}\right)=V\left[\left(M \geq M_{1}\right) \text { and }\left(M \geq M_{2}\right) \text { and } \ldots \text { and }\left(M \geq M_{k}\right)\right] \\
& =\min \quad V\left(M \geq M_{i}\right), i=1,2, \ldots, k
\end{aligned}
$$

- Assume that $d\left(X_{i}\right)=\min V\left(S_{i} \geq S_{k}\right)$ for $k=1,2, \ldots, n ; k \neq i$. Then, the weight vector isgiven by $W^{\prime}=\left(d^{\prime}\left(X_{1}\right), d^{\prime}\left(X_{2}\right), \ldots, d^{\prime}\left(X_{n}\right)\right)^{T}$ where $X_{i}=(i=1,2, \ldots, n)$ are $n$ elements. Via normalization, the normalized weight vectors are 


$$
W=\left(d\left(X_{1}\right), d\left(X_{2}\right), \ldots, d\left(X_{n}\right)\right)^{T}
$$

Where $W$ is a vector of crisp numbers.

\section{EMPIRICAL CASE AND RESULTS}

This study organized the hybrid structure model to evaluate contact center outsourcing partners such as Figure 1. The top level, the goal of decision making, was set with the evaluation of outsourcing partners, and the four perspectives like financial, customer, operational process, and learning and growth perspectives were allocated as evaluation criteria in the second level. And the third level included the sub-criteria of each perspective. The financial perspective has the three subcriteria such as increase in revenues, labor costs and incentives. The customer perspective includes average waiting time on contacts, average holding time on contacts and first contact resolution. The perspective of operational process has occupancy, contacts answered and handling time per customer. And the sub-criteria of learning and growth perspective are composed of average time of appraisal, number of training sessions and number of surveys and feedback. The lowest level contains the alternatives to be evaluated, namely three different outsourcing partners.A survey was conducted on the decision makers of outsourcing partner selection with the two types of questionnaires based on the hybrid structure shown in Figure 1. The first type of two questionnaires was distributed to decide the weights of evaluation criteria and subcriteria, and the second questionnaire consists of questions to know the preferences of outsourcing partners according to the evaluation sub-criteria.

In this study, all pairwise comparison judgments were represented as fuzzy triangular numbers. Then, the fuzzy geometric mean method (Buckley, 1985)was used to aggregate the fuzzy evaluated score from eleven evaluators. After obtaining the fuzzified pairwise comparison matrices, relative importance (weights) of the criteria and sub-criteria were calculated through equations (2) to (5). The priority weights of criteria (shown in Table 2) indicate thatcustomer perspective is the most important criteria (0.390) in evaluating and selecting outsourcing partners, followed by financial perspective (0.259), operational process perspective(0.189), and learning and growth perspective(0.163).By following the same procedure as described above, all sub-criteria were compared with respect to each of the corresponding criteria, and the priority weights of sub-criteria were calculated as given in the second column of Table 2.Then, the global composite priority weights of sub-criteria (shown in Figure2) were calculated by multiplying the priority weights of sub-criteria with those of their corresponding criteria in the next higher level of the hierarchy.

To get the ranks of outsourcing partners, it requires calculating the weights of criteria, sub-criteria, and alternatives. The scores of alternatives on the sub-criteria should be multiplied by the weights of the upper level, and then the resulted scores should be again multiplied by the weights of the top level. The final evaluation results on outsourcing partners through these calculation processes are shown in the third column of Table 2. Based on the overall scores of the three outsourcing partners shown in Table 2, it can be concluded that outsourcing partner B has the highest overall score among three alternatives. Therefore, it must be selected as the best outsourcing partner satisfying all evaluation criteria.

Table 2: Overall Scores of Contact Center Outsourcing Partners

\begin{tabular}{|c|c|c|c|c|}
\hline \multirow{2}{*}{ Criteria } & Sub-Criteria & \multicolumn{2}{|c|}{ Contact Center Outsourcing Partner } \\
\cline { 2 - 4 } & A & 0.342 & B & C \\
\hline $\begin{array}{c}\text { Financial } \\
\text { Perspective }\end{array}$ & $\begin{array}{c}\text { Increase in revenues } \\
(\mathrm{L}=0.492)(\mathrm{G}=0.128)\end{array}$ & 0.379 & 0.333 \\
\cline { 2 - 5 }$(\mathrm{G}=0.259)$ & $\begin{array}{c}\text { Labor costs } \\
(\mathrm{L}=0.277)(\mathrm{G}=0.072)\end{array}$ & 0.324 & 0.327 \\
\hline
\end{tabular}




\begin{tabular}{|c|c|c|c|c|}
\hline & $\begin{array}{c}\text { Incentives } \\
(\mathrm{L}=0.231)(\mathrm{G}=0.060)\end{array}$ & 0.333 & 0.381 & 0.286 \\
\hline \multirow{3}{*}{$\begin{array}{c}\text { Customer } \\
\text { Perspective } \\
(\mathrm{L}=\mathrm{G}=0.390)\end{array}$} & $\begin{array}{l}\text { Average waiting time on contacts } \\
(\mathrm{L}=0.167)(\mathrm{G}=0.065)\end{array}$ & 0.418 & 0.357 & 0.226 \\
\hline & $\begin{array}{l}\text { Average holding time on contacts } \\
(\mathrm{L}=0.524)(\mathrm{G}=0.204)\end{array}$ & 0.411 & 0.346 & 0.243 \\
\hline & $\begin{array}{l}\text { First contact resolution } \\
(\mathrm{L}=0.309)(\mathrm{G}=0.120)\end{array}$ & 0.284 & 0.485 & 0.231 \\
\hline \multirow{3}{*}{$\begin{array}{c}\text { Operational } \\
\text { Process } \\
\text { Perspective } \\
(\mathrm{L}=\mathrm{G}=0.189)\end{array}$} & $\begin{array}{c}\text { Occupancy } \\
(\mathrm{L}=0.463)(\mathrm{G}=0.087)\end{array}$ & 0.294 & 0.533 & 0.174 \\
\hline & $\begin{array}{c}\text { Contacts answered } \\
(\mathrm{L}=0.308)(\mathrm{G}=0.058)\end{array}$ & 0.363 & 0.272 & 0.365 \\
\hline & $\begin{array}{l}\text { Handling time per customer } \\
(\mathrm{L}=0.229)(\mathrm{G}=0.043)\end{array}$ & 0.386 & 0.213 & 0.401 \\
\hline \multirow{3}{*}{$\begin{array}{c}\text { Learning and } \\
\text { Growth } \\
\text { Perspective } \\
(\mathrm{L}=\mathrm{G}=0.163)\end{array}$} & $\begin{array}{c}\text { Average time of appraisal } \\
(\mathrm{L}=0.237)(\mathrm{G}=0.039)\end{array}$ & 0.335 & 0.305 & 0.360 \\
\hline & $\begin{array}{l}\text { Number of training sessions } \\
(\mathrm{L}=0.185)(\mathrm{G}=0.030)\end{array}$ & 0.394 & 0.343 & 0.264 \\
\hline & $\begin{array}{l}\text { Number of surveys and feedback } \\
(\mathrm{L}=0.578)(\mathrm{G}=0.094)\end{array}$ & 0.173 & 0.355 & 0.472 \\
\hline & Overall Scores & 0.337 & 0.374 & 0.289 \\
\hline
\end{tabular}

Note: (L) denotes local weights and $(\mathrm{G})$ denotes global weights.



Figure 2: Global Priority Weights of Sub-Criteria.

\section{CONCLUSIONS}

With the rapid growth of contact center outsourcing, the Korean government has introduced certification system of contact center service providers to provide high quality customer service. It may reflect the imperative importance of reliable and realisticevaluation and selection model of contact center outsourcing partners. In this point, this study proposed a decision framework for performance evaluation of contact center outsourcing partners based on BSC and FAHP method.An empirical case study is used to exemplify applicabilityof the proposed approach.This study is expected tohelp organizations in selecting the most suitableoutsourcing partners and in evaluating outsourcing partner performance.Despite of these practical implications, as it was based on the limited small number of cases, it may be difficult to generalize the results. 
Also, this study did not consider the specific characteristics and strategic factors on the view of outsourcing company. Therefore, future research should replicate and extendthis studyby considering different cases and conditions.

\section{ACKNOWLEDGEMENTS}

This paper was supported by Wonkwang University in 2018.

\section{REFERENCES}

1. Adroit Market Research. (2019). Global Contact Center Outsourcing Market Size by Service Type, by Industry, by Application and Geography Forecast 2018 to 2025.

2. Anton, J. (1997). Call Center Management: By the Numbers. West Lafayette, Ind.: Purdue University Press.

3. Buckley, J. J. (1985). Fuzzy hierarchical analysis. Fuzzy Sets and Systems, 17(3), 233247.

4. Chan, F. T. S. and Kumar, N. (2007). Global supplier development considering risk factors using fuzzy extended AHP-based approach. OMEGA, 35(4), 417431.

5. Chang, D. Y. (1996). Applications of the Extent Analysis Method on Fuzzy AHP. European Journal of Operational Research, 95(3), 649655

6. Cheong, K., Kim, J. and So, S. (2008). A Study of Strategic Call Center Management: Relationship between Key Performance Indicators and Customer Satisfaction. European Journal of Social Sciences, 6(2), 268276.

7. El Khayyam, Y. and Herrou, B. (2018). CCAHP: A New Method for Group Decision Making Application on Supply Chain Dashboard Design. International Journal of Mechanical and Production Engineering Research and Development, 8(2), 13031318.

8. Feinberg, R., Hokama, L., Kadam, R. and Kim, I. (2002). Operational determinants of caller satisfaction in the banking/financial services call center. International Journal of Bank Marketing, 20(4), 174180.

9. Kaplan, R. S. and Norton, D. P. (1992). The balanced scorecard: measures that drive performance. The Harvard Business Review, 70(1), 7179.

10. Korean Agency for Technology and Standards. (2006). KS A 0976-1 Call Center Service.

11. Namasivayam, S. (2004). Profiting from business process outsourcing. IT Professional, 6(1), 1218.

12. Ratna, S. A. N. A. T. A. N., A. Subham, and M. Saiuddin. "Assessment of lean performance of manufacturingcells in an SME using AHP." Int. J. Mech. Prod. Eng. Res. Dev.(IJMPERD) 8.3 (2018): 435440.

13. RAMAN, R. SUNDARA, and G. SHANKARANARAYANAN. "PRIORITIZATION OF THE VIQ THINGS INSIDE SIRE PROGRAM FOR AN OIL TANKER TRANSPORT."International Journal of Mechanical and Production Engineering Research and Development (IJMPERD) 8.1, Feb 2018, 857862.

14. Saaty, T. L. (1980). The Analytic Hierarchy Process. New York: McGraw-Hill.

15. Soh, SH. (2010). A decision model for evaluating third-party logistics providers using fuzzy analytic hierarchy process. African Journal of Business Management, 4(3), 339349.

16. Tien, YuSeng, et al. "DecisionMakingwith Multi-CriteriaAssessment: How Firms to Select Appropriate Collaboration Partner?." International Journal of Business Management \&Research (IJBMR) ISSN (P) (2016): 22496920. 
17. Umamaheswari, A., and P. Kumari. "Fuzzy TOPSIS and Fuzzy VIKOR methods using the Triangular Fuzzy Hesitant Sets." International Journal of Computer Science Engineering and Information Technology Research 4 (2014): 1524.

18. Zadeh, L. A. (1965). Fuzzy Sets. Information and Control, 8(3), 338353. 